\title{
Vitreous Levels of the Insulin-like Growth Factors I and II, and the Insulin-like Growth Factor Binding Proteins 2 and 3, Increase in Neovascular Eye Disease
}

\author{
Studies in Nondiabetic and Diabetic Subjects
}

\author{
R. Meyer-Schwickerath, ${ }^{\star}$ A. Pfeiffer, ${ }^{\star}$ W. F. Blum, ${ }^{*}$ H. Freyberger, ${ }^{\star}$ M. Klein," C. Lösche, ${ }^{\|}$R. Röllmann, ${ }^{\star}$ and H. Schatz ${ }^{\ddagger}$ \\ ${ }^{*}$ Augenklinik Knappschaftskrankenhaus Langendreer and ${ }^{\ddagger}$ Medizinische Klinik und Poliklinik, Klinikum Bergmannsheil, Ruhr- \\ Universität Bochum, 44789 Bochum 1; § Kinderklinik der Universität Tübingen 72070 Tübingen and "Augenklinik des Evangelisches \\ Krankenhaus Duisburg-Nord, 47169 Duisburg, Germany
}

\begin{abstract}
Retinal capillary nonperfusion results in neovascularization of the eye, which is restricted to the retina in less severe cases and progresses to the anterior chamber and the iris angle in the most advanced case, called rubeosis. This angioneogenesis may be induced by the release of retinal growth factors into the vitreous. This study compared levels of the IGF-I and IGF-II, and of the IGF binding protein-2 (IGFBP-2) and IGFBP-3 in vitreous from three groups with different degrees of retinal ischemia, as judged by the extent of neovascularization: a control group without new vessel formation, retinal neovascularization in patients with proliferative diabetic retinopathy, and massive ischemia of various causes resulting in rubeosis. IGF-I and IGFBP-3 were increased 10 - and 13 -fold in rubeosis $(P \ll 0.01)$ compared with no ischemia ( $n=10)$, while IGF-II and IGFBP-2 were elevated 2.7 - and 4.3-fold $(P<0.01)$. Within the rubeosis group similar changes were observed independently of the cause of ischemia, which was central vein occlusion, ischemic ophthalmopathy, or intraocular tumor in seven cases and diabetic retinopathy in three samples from two patients. Vitreous from patients with proliferative diabetic retinopathy but without rubeosis $(n=16)$ contained 2.5- and 2.2fold elevated levels of IGF-I and of IGFBP-2 $(P<0.05)$, while IGF-II and IGFBP-3 were increased 1.4- and 1.6-fold, which was not significant. We conclude that: $(a)$ ischemia appears to be a strong stimulus for the local production of IGF-I and -II and of IGFBP-2 and -3 in the eye. (b) Changes in IGF-I and IGFBP-2 in proliferative diabetic retinopathy may be secondary to local ischemia rather than being specific for diabetic retinopathy. (c) IGF-I and IGFBP-3 may play a role in mediating angioneogenesis in the eye. (J. Clin. Invest. 1993.92:26202625.) Key words: growth substances • eye disease, ischemic • diabetes $\bullet$ diabetic retinopathy $\bullet$ angiogenesis
\end{abstract}

\section{Introduction}

Tissue ischemia has been proposed to represent the stimulus that initiates the angioneogenesis observed in wound healing $(1,2)$. A similar concept was proposed to explain neovascular-

Address correspondence to Dr. Andreas Pfeiffer, Medizinische Klinik und Poliklinik, Klinikum Bergmannsheil, Ruhr-Universität Bochum, Gilsingstrasse 14, D-4630 Bochum 1, Germany.

Received for publication 20 April 1993 and in revised form 26 July 1993.

J. Clin. Invest.

(C) The American Society for Clinical Investigation, Inc. $0021-9738 / 93 / 12 / 2620 / 06 \quad \$ 2.00$

Volume 92, December 1993, 2620-2625 ization in the eye (3-6), which provides an ideal clinical setting to directly study tissue ischemia. The observation that capillary nonperfusion precedes the development of new vessels led to the proposal that it is the ischemic retina itself that triggers the angioneogenetic response. Moreover, the degree of capillary nonperfusion quantified by fluorescein angiography correlated with the likelihood of developing neovascularization in diabetic subjects ( 3 ). The activity produced by the retina was assumed to be diffusable since extensive capillary nonperfusion was associated with rubeosis, thus producing new vessel growth from a tissue as far anterior as the surface of the iris. In a systematic study, the greatest degree of capillary nonperfusion was observed in patients who developed iris and angle neovascularization, the second greatest degree of nonperfusion in patients with neovascularization at the optic disc, and the least degree of capillary nonperfusion in patients with neovascularization away from the optic disk (4).

Numerous mitogenic and angiogenic factors have been demonstrated in the eye including IGF, transforming growth factor- $\beta$, fibroblast growth factor, and tumor necrosis factor ( 2 , 7). However, little is known about the growth factor responses occurring in the eye in response to ischemia, particularly in a clinical setting. The ability to monitor and to grade angioneogenetic responses within the eye as well as the ability to aspirate vitreous cavity fluid bathing the angiogenetic tissue makes this an ideal setting in which to investigate the development of new vessel growth. The most frequent cause of angioneogenesis in the eye is proliferative diabetic retinopathy $(3,8)$. Growth hormone is markedly elevated in diabetics with poor metabolic control and appears to play a role in the development of diabetic retinopathy, although the precise manner is unclear $(8$, 9). The IGFs, IGF-I and IGF-II, are thought to mediate many responses to growth hormone. Merimee and coworkers $(8,10)$ demonstrated increased levels of IGF-I, but not IGF-II, in the vitreous of diabetic patients with proliferative diabetic retinopathy. This study did not include subjects with iris neovascularization.

The ability of IGF-I to stimulate retinal angioneogenesis upon intravitreal application was recently described in the rabbit, where IGF-I was approximately equipotent with basic fibroblast growth factor (11). Particularly, intravitreal injections of IGF-I had a dramatic effect on retinal vessels, causing a rapid disruption of the blood-retinal barrier and neovascularization beginning at the optic disc and progressing to fibrovascular proliferation, which caused retinal traction and detachment similar to the changes seen in proliferative diabetic retinopathy (11). A second group of animals, which were treated locally by use of a slow release capsule positioned on the retina, showed areas of vascular proliferation and endothelial thickening in the vicinity of the capsule, thereby confirming a specific effect 
of IGF-I (11), the extent of which depended on the site of application. Iris neovascularization was not described in these experiments. Stimulating effects of IGF-I on proliferation of the human embryonic cornea in a tissue culture system were also described previously (12), confirming a proliferative effect of this growth factor in ocular tissues.

In the eye, the diffusable factor(s) associated with angioneogenesis should be expected to be present within the vitreous (7). Vitrectomy is one type of therapy in patients with advanced proliferative diabetic retinopathy and also in other diseases of the eye not associated with angioneogenesis, such as proliferative vitreo-retinopathy, which involves marked proliferation of connective tissue. To investigate the response of the IGFs to tissue ischemia, we determined the levels of IGF-I, IGF-II, and of the IGF binding proteins (IGFBP-2 and IGFBP$3)^{1}$ in the vitreous of diabetic patients with proliferative retinopathy, in patients with proliferative vitreo-retinopathy, and in subjects with rubeosis iridis due to proliferative diabetic retinopathy and other causes such as central vein occlusion and ischemic ophthalmopathy. The clinical syndrome of iris neovascularization was thus used as a marker of the severity of retinal ischemia. Based on the studies described above $(3,4)$, patients having rubeosis iridis should be expected to have the greatest degree of retinal capillary nonperfusion, while patients with more localized retinal neovascularization such as observed in diabetic proliferative retinopathy should have less severe retinal ischemia.

\section{Methods}

Subjects. The study was approved by the ethical commission of the University of Bochum. Patients having pars plana vitrectomy or enucleation of an eye according to an ophthalmologic indication were studied (Table I). Written or verbal informed consent was obtained from the patients and the patient histories were recorded. The diabetic patients all had proliferative diabetic retinopathy and had undergone previous laser coagulation of the retina. No open eye surgery had been performed on the patients for 2 mo before the study.

Nonischemic surgical controls (no ischemia). Three female and seven male patients were studied; mean age was $53 \pm 7$ yr. Pars plana vitrectomy was performed because of proliferative vitreoretinopathy in five cases, painful secondary amaurosis $7-14 \mathrm{yr}$ after a trauma or perforation in three cases, and enucleation because of basalioma of the lower lid and after fatal trauma in one case each. The absence of new vessel formation was confirmed histologically. One eye from each of the 10 patients was analyzed.

Controls. Vitreous was also obtained from one eye of 10 subjects in the course of pathological dissection. None of these subjects had ophthalmologic disease. Vitreous was obtained $24-48 \mathrm{~h}$ after death. This group served as a second control group. Because some degradation of IGFBPs or of IGF-I and IGF-II cannot be excluded, the values determined in these subject may be below normal. However, this group illustrates the lower normal limit, and supports the values determined in the nonischemic control group as being close to normal. The IGFBPs are rather stable in solution at room temperature as are IGF-I and IGF-II bound to them, such that decreases occurring in such a relatively inert fluid as vitreous may be expected to be rather small. This group was not used for statistical calculations because of the different conditions under which vitreous was obtained.

Rubeosis. The patients (three male, six female) had rubeosis iridis and extensive new vessel formation on slit lamp examination. Neovas-

1. Abbreviation used in this paper: IGFBP, insulin-like growth factor binding protein. cular glaucoma after thrombosis of the central vein was present in five patients. Two patients had neovascular glaucomas because of diabetic proliferative retinopathy. One patient had a melanoma and one patient had ischemic ophthalmopathy after carotid occlusion. The mean age of the nine patients was $75 \pm 2$ yr. From one patient two eyes were obtained. A mean value was calculated from data of both eyes and used in this report.

Diabetes. Six male and eight female type II, and two male type I, diabetic patients with proliferative diabetic retinopathy but without rubeosis were studied $(n=16)$. 11 patients had neovascularization on the disk (NVD) and on the retina (NVE), 4 patients had NVD, and 1 patient had NVE. The mean age was $61 \pm 4 \mathrm{yr}$ and the duration of diabetes was $24.7 \pm 1.9 \mathrm{yr}$. The group included only one patient in whom diabetes had been diagnosed $<20$ yr before vitrectomy. In two of the patients serum creatinine was elevated to 7.1 and $4.1 \mathrm{mg} / \mathrm{dl}$, and the others had a normal mean serum creatinine of $1.2 \pm 0.1 \mathrm{mg} / \mathrm{dl}$.

Vitreous samples. Vitreous was aspirated $(0.2-0.7 \mathrm{ml})$ at the beginning of pars plana vitrectomy. The fluid was removed from the central anterior vitreous by an outcome before any irrigating fluid was infused into the eye. Vitreous samples in painful neovascular glaucoma were performed by puncture of the globe immediately after enucleation of the eye. The material was spun for $15 \mathrm{~min}$ at $13,000 \mathrm{~g}$ in a refrigerated centrifuge at $4^{\circ} \mathrm{C}$ to remove particles and then stored in aliquots at $-70^{\circ} \mathrm{C}$ until the assays were performed. Hemorrhagic samples were excluded from the analysis $(n=4)$.

$I G F-I R I A$. For IGF-I determinations a polyclonal antibody (kind gift of Drs B. Breier and P. Gluckman, University of Auckland, Auckland, New Zealand) produced in rabbits was used (13). This antibody was of high affinity (half-maximal displacement at $1.1 \mathrm{ng} / \mathrm{ml}$; detection limit, $10 \mathrm{pg} / \mathrm{ml}$ ) and high specificity (cross reactivity with IGF-II $<0.05 \%)$. The standards and the tracers were prepared from recombinant human (h)IGF-I (Kabi-Pharmacia, Stockholm, Sweden) using the chloramine $T$ method for the latter (14). The interference of IGFBPs in the RIA could be completely blocked by performing the assay in the presence of a large excess of IGF-II. For dissociation of IGFs from IGFBPs samples were acidified by addition of $10 \%$ of their volume: $0.5 \mathrm{~mol} /$ liter phosphoric acid and appropriate dilutions were made with $0.1 \mathrm{~mol} /$ liter sodium phosphate buffer, $\mathrm{pH} 2.8$, containing $0.1 \% \mathrm{BSA}(\mathrm{wt} / \mathrm{vol}), 0.02 \%$ sodium azide $(\mathrm{wt} / \mathrm{vol})$, and $0.2 \%$ Triton $\mathrm{X}-100$ (vol/wt). The IGF-I antiserum $(1: 50,000)$ and tracer $(20,000$ $\mathrm{cpm} / \mathrm{ml}$ ) were dissolved in the same buffer except that the $\mathrm{pH}$ was 7.8 (assay buffer). The antiserum dilution contained in addition $250 \mu \mathrm{g} /$ liter recombinant hIGF-II to block IGFBP (15) and $50 \mathrm{mg} /$ liter rabbit gamma globulin (Sigma, Munich, Germany). $100 \mu$ l of the sample, the first antibody, and the tracer was incubated for $2 \mathrm{~d}$ at $4^{\circ} \mathrm{C}$ before adding the second antibody (donkey anti-rabbit IgG; Gesellschaft für Immunchemie und -Biologie, Hamburg, Germany) diluted in $4 \%$ polyethyleneglycol ( $w / / v o l)$. After $1 \mathrm{~h}$ the precipitate was collected by centrifugation and washed once before counting. The intra-assay and inter-assay coefficients of variation were 3.1 and $8.1 \%$, respectively.

$I G F-I I$ RIA. The antibody was developed against the synthetic $\mathrm{C}$ domain of hIGF-II (hIGF-II [33-40]) as described previously (16). It was of high specificity showing a crossreactivity with hIGF-I of $<0.05 \%$. The assay protocol was identical to the IGF-I RIA, except that interfering IGFBP was blocked with an excess of hIGF-I (16). The intra- and inter-assay CV were 3.6 and $12.2 \%$, respectively.

$I G F B P-2 R I A$. IGFBP-2 was measured by a novel specific RIA. Briefly, a polyclonal antibody against a synthetic partial sequence (hIGFBP-2[176-190]) was produced in rabbits. The tracer was prepared by radioiodination of ( Tyr $)^{0}$-hIGFBP-2(176-190). For preparation of standards hIGFBP-2(176-190) was calibrated with recombinant hIGFBP-2 (kindly supplied by Dr. Schwander, Basel, Switzerland). The samples were diluted in assay buffer (see IGF-I RIA) and the assay was performed as described for IGF-I. Details of the assay will be published elsewhere.

$I G F B P-3 R I A$. IGFBP-3 was measured by RIA directed against the acid-stable IGFBP-3 binding subunit (IGFBP-3) as described previously (17). 
Statistical calculations. Comparisons between groups were made by analysis of variance and Duncan's multiple range test. The correlation between groups was calculated by linear regression analysis of untransformed values.

\section{Results}

Vitreous fluid aspirates from four groups were compared: patients with massive ischemic eye disease resulting in angle and/ or iris neovascularization ( rubeosis), diabetic patients with proliferative retinopathy but without rubeosis or neovascular glaucoma, a group without neovascularization in the eye that was operated on for eye diseases without ischemic causes, and a fourth group in which vitreous was obtained during autopsy from subjects without ocular diseases. In this latter group vitreous was obtained $24-48 \mathrm{~h}$ after death. Since a decrease of the components measured in vitreous cannot be excluded in this group due to the delay between death and withdrawal of the sample (see Methods), it was decided not to include this group in the statistical analysis. The values are intended as an additional control to give an idea of "normal" levels independently of the nonischemic control group since an elevation of the components measured due to nonischemic eye disease cannot be excluded in the nonischemia group.

$I G F-I$. Levels of IGF-I ranged between 1.0 and $45.6 \mathrm{ng} / \mathrm{ml}$ in the vitreous from the different groups, which is between 1.5 and $22 \%$ of the levels observed in serum (18). IGF-I was increased 4-10-fold in the rubeosis group compared with either nonischemic eye disease or diabetic subjects (Fig. 1). Samples from two patients with diabetic retinopathy and neovascular glaucoma contained 15.5 and $5.9 \mathrm{ng} / \mathrm{ml}$ IGF-I, which was in the range observed in massive ischemia without diabetes. Diabetic retinopathy without rubeosis was associated with 2.4 -fold elevated levels of IGF-I, which was significantly higher than

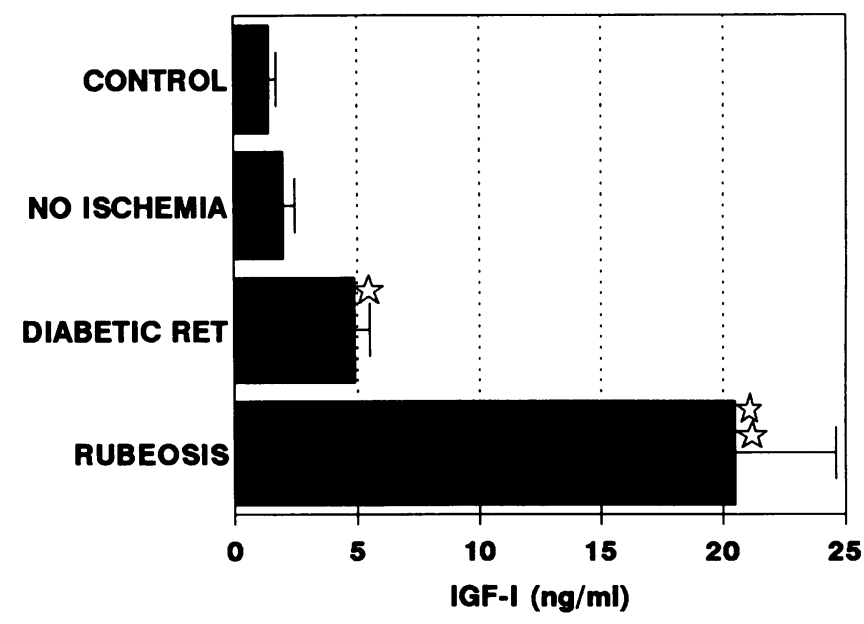

Figure 1. Levels of IGF-I in vitreous fluid of autopsy samples ( $\mathrm{CON}$ $T R O L, n=10$ ), of patients with nonischemic eye disease ( $N O$ ISCHEMIA, $n=10$ ), of patients with proliferative diabetic retinopathy (DIABETIC RET, $n=16)$, and of patients with neovascularization of the anterior eye ( $R U B E O S I S, n=9)$ secondary to massive ischemia. The control group consisting of autopsy samples was not included in the statistical analysis because of differences in sampling conditions. Vitreous from the diabetic retinopathy group $\left({ }^{*} P<0.05\right)$ and the rubeosis $\left({ }^{* *} P \ll 0.01\right)$ group was significantly different from the no ischemia group.

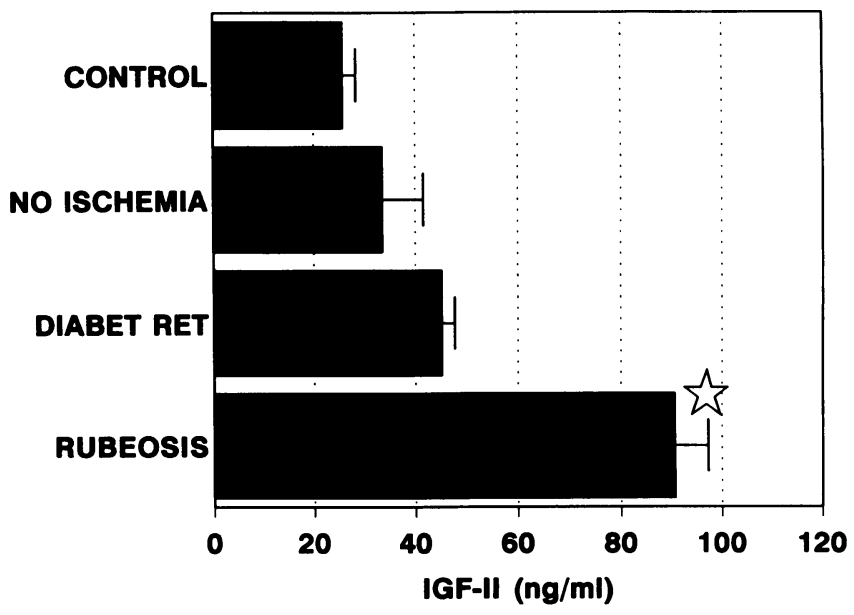

Figure 2. Levels of IGF-II in vitreous fluid. For further explanation see legend to Fig. 1. Rubeosis vs. no ischemia, ${ }^{*} P<0.01$.

values observed in the nonischemia group. However, the IGF-I levels in diabetic retinopathy without rubeosis were only onefourth of those seen in rubeosis. The autopsy samples contained only slightly less IGF-I than the nonischemia group, which confirms that this latter control group did not show marked elevations of IGF-I above normal values.

$I G F-I I$. Levels of IGF-II in the vitreous ranged between 9 and $116 \mathrm{ng} / \mathrm{ml}$, which is between 5 and $18 \%$ of the levels observed in serum in the respective age group (18). IGF-II was significantly $(P<0.001)$ higher in the rubeosis group as compared with diabetic or nonischemia samples (Fig. 2). Samples from two diabetic patients with rubeosis contained 89 and 59 $\mathrm{ng} / \mathrm{ml}$ IGF-II, which was in the range of the nondiabetic rubeosis group. There was no statistical difference between diabetic and nonischemia samples. The samples obtained on autopsy contained $24 \%$ lower levels of IGF-II than the nonischemia group, which was not statistically different.

IGFBP-2. Levels of IGFBP-2 ranged between 19 and 994 $\mathrm{ng} / \mathrm{ml}$. In the vitreous of nonischemia controls and in the autopsy samples, they were 35 and $25 \%$ of those measured in serum of adult controls (19) and thus were present at relatively high levels. IGFBP-2 was significantly $(P<0.001)$ higher in the vitreous of the rubeosis group as compared with samples from diabetic or control patients (Fig. 3). Diabetic patients with rubeosis had 443 and $502 \mathrm{ng} / \mathrm{ml}$ IGFBP-2 in the vitreous, which was in the range of the rubeosis group. Diabetic patients without rubeosis had 2.2 times higher levels of IGFBP-2 in the vitreous than nonischemic controls, which was statistically significant $(P<0.01)$. The autopsy samples were $27 \%$ lower than those in the nonischemia group, which was nonsignificant.

IGFBP-3. Levels of IGFBP-3 ranged overall between 21 and $4,158 \mathrm{ng} / \mathrm{ml}$. They were 91 and $156 \mathrm{ng} / \mathrm{ml}$ in the autopsy and nonischemia groups, which was between 3 and $5 \%$ of normal serum levels (19). Levels in autopsy samples were $42 \%$ lower than those in the nonischemic control group. Diabetic retinopathy was associated with a 57\% increase above levels in the nonischemia group, which was not statistically significant. A striking increase was seen in vitreous levels of IGFBP-3 in the rubeosis group compared with samples from diabetic or nonischemic control subjects (Fig. 4). Again, the two diabetic patients with rubeosis had very high levels of IGFBP-3, 2,193 and $497 \mathrm{ng} / \mathrm{ml}$. 


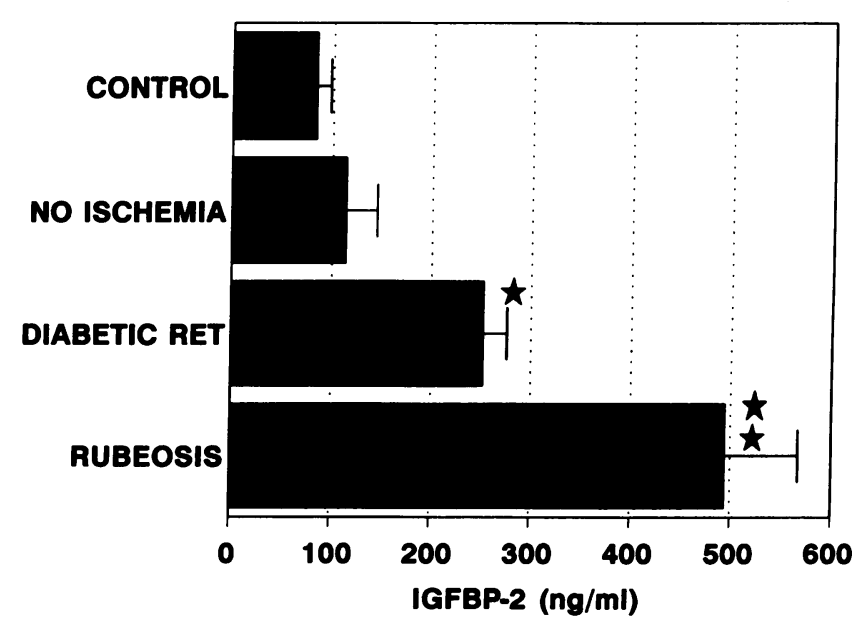

Figure 3. Levels of IGFBP-2 in vitreous fluid. For further explanations see legend to Fig. 1 . diabet ret vs. no ischemia, ${ }^{*} P<0.05$; rubeosis vs. no ischemia, ${ }^{* *} P<0.01$.

Correlation of IGF-I, IGF-II, IGFBP-2, and IGFBP-3. Table I shows a remarkably high linear correlation among all of the components of the IGF system determined in the vitreous of the nonischemia group. In serum the best correlation between IGFBP-3 and IGF-I is obtained when IGFBP-3 is plotted against the log IGF-I. This was not observed in vitreous where the coefficient of correlation for $\log$ (IGF-I) against IGFBP-3 (linear) was $r^{2}=0.57$, as compared with the linear correlation of $r^{2}=0.70$. Samples with markedly elevated levels of IGFBP3 and IGF-I deviated from this correlation and showed a proportionately stronger increase in IGFBP-3.

The high correlations among the components of the IGF system were generally observed to a much lesser degree in samples obtained from the diabetic retinopathy or the rubeosis group (Table I). Thus, the correlation of IGF-I with the binding proteins IGFBP-2 and -3 was lost as compared with nonischemia controls. Remarkably, a high correlation was observed between IGF-II and IGFBP- 2 in the diabetic retinopathy group but not in the rubeosis group. A high correlation among the bindings proteins was also maintained in the dia-

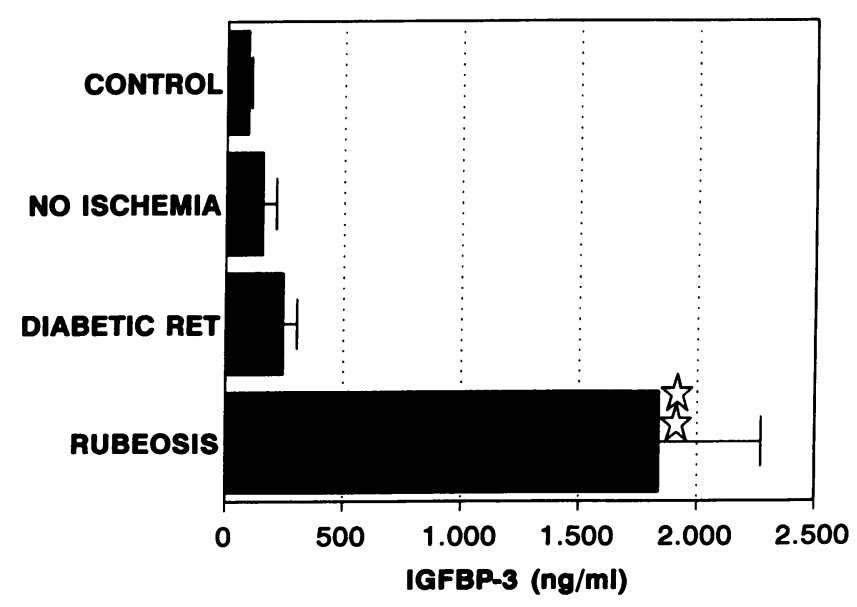

Figure 4. Levels of IGFBP-3 in vitreous fluid. For further explanations see legend to Fig. 1. Rubeosis vs. no ischemia, ${ }^{*} P \ll 0.01$.
Table I. Linear Coefficients of Correlation among Patients Studied

\begin{tabular}{llcc}
\hline \multicolumn{1}{c}{ Components } & $\begin{array}{c}\text { Nonischemia } \\
(n=10)\end{array}$ & $\begin{array}{c}\text { Diabetic retinopathy } \\
(n=16)\end{array}$ & $\begin{array}{c}\text { Rubeosis } \\
(n=9)\end{array}$ \\
\hline IGF-I/IGF-II & $0.78^{*}$ & 0.46 & 0.53 \\
IGF-I/IGFBP-2 & $0.83^{*}$ & 0.36 & 0.11 \\
IGF-I/IGFBP-3 & $0.70^{\ddagger}$ & 0.22 & 0.21 \\
IGFII-IGFBP-2 & $0.91^{\S}$ & $0.80^{\S}$ & 0.11 \\
IGF-II/IGFBP-3 & $0.85^{\ddagger}$ & 0.30 & 0.35 \\
IGFBP-2/IGFBP-3 & $0.65^{\ddagger}$ & $0.72^{*}$ & 0.35 \\
\hline
\end{tabular}

Data are linear coefficients of correlation $\left(r^{2}\right)$ among the components indicated on the left. ${ }^{*} P<0.01 ;{ }^{\ddagger} P<0.05 ;{ }^{\S} P<0.001$.

betic retinopathy group even though increases were observed for IGFBP-2 but much less so for IGFBP-3.

\section{Discussion}

The eye provides a unique window in which to observe angiogenetic responses as a marker of tissue ischemia, allowing assessment of its extent and severity. The aim of this study was to assess the response of IGFs and their binding proteins to ischemia. Shimizu et al. (4) and other groups $(3,20)$ established that the extent of neovascularization correlates with the degree of capillary nonperfusion. Moreover, diffusible angiogenic factors must be present in vitreous, since vascularization of the angle and iris is provoked by retinal ischemia in the most advanced cases. Based on these findings three groups expected to have different degrees of ischemia were compared: a massive ischemia group as documented by neovascularization of the anterior eye, a moderate ischemia group with proliferative diabetic retinopathy, and a low/nonischemia group with nonischemic eye diseases. Additionally, autopsy samples of vitreous were used to exclude that nonischemia-related elevations of IGFs or IGFBPs occurred in the nonischemia group taken as control.

The levels of IGF-I in nonischemia and autopsy samples were both $2 \%$ of serum levels, and those of IGF-II were 6 and $5 \%$, respectively. Levels of IGFBP-3 in nonischemia and autopsy vitreous were 5 and $3 \%$ of those in serum of age-matched controls (18). The ratios of IGFBP-3 over IGF-I and IGF-II were 0.66 in nonischemia and 0.5 in autopsy samples, which is closely comparable to the value of 0.73 found in serum (18). The amounts of these proteins in vitreous would be compatible with a spill-over from serum levels, although a local production of IGF-I has been established by demonstration of its mRNA in the retina (7). Values of IGFBP-2 in nonischemia and autopsy vitreous were 35 and $25 \%$ of those in serum (19), and thus substantially higher than the other components of the IGF system, which appears to point to a local production of this protein. Remarkably, there was a high degree of correlation among all four components determined in the nonischemia group.

In severe ischemia resulting in rubeosis iridis with secondary neovascular glaucoma, the prominent observation was a 10- and 2.6-fold elevation of IGF-I and IGF-II, and a 4.3- and 12.6-fold elevation of IGFBP-2 and IGFBP-3, compared with nonischemia controls. The increase of the binding proteins exceeded that of the growth factors, resulting in an increase of the 
molar ratio of IGFBP-3 over IGF-I plus IGF-II to 2.7, which is 4-fold higher than the ratio in the nonischemia group of 0.66 . Consequently, one would expect an increase in the IGFBPbound fraction of both growth factors. In view of the higher affinity of IGF-II for IGFBP-2, this factor may predominantly be bound to this protein, while IGF-I should primarily bind to IGFBP-3. However, the concentrations of other IGF-binding proteins, like IGFBP-1, IGFBP-4, IGFBP-5, and IGFBP-6, are not known at present and may substantially alter the overall situation.

The nondiabetic patients with rubeosis had normal plasma glucose levels and are not expected to show substantial alterations of the release of human growth hormone or insulin, which are known to affect levels of IGFs or of IGFBPs (21). The marked elevations of IGFs and IGFBPs therefore may represent local regulatory responses to tissue ischemia. Since IGF-I is able to augment the synthesis of IGFBP-2 and IGFBP$3(21-23)$, it is a possible candidate to direct locally the changes of these binding proteins. The high correlation among IGF-I and the IGFBPs was lost in rubeosis. If IGF-I regulated the IGFBPs exclusively, such a correlation might be expected. Therefore, other regulatory mechanisms may well be operative, and this question requires further studies with isolated cell systems. Another possible source of increases in IGFs and IGFBPs in rubeosis is serum. Angioneogenesis is accompanied by a breakdown of the blood-retina barrier, and therefore, some contribution by serum may be present. However, the ratios of IGFs and IGFBPs differed three- to fourfold between serum and vitreous in rubeosis. One would therefore have to assume different permeabilities of retinal blood vessels for each IGF and for each IGFBP in order to explain the small increase in IGF-II and IGFBP-2 and the large increase in IGF-I and IGFBP-3. Therefore, local production is the most probable source of IGFs and IGFBPs, which is also supported by the occurrence of the messenger RNAs for these components in the eye (see below).

Patients with proliferative diabetic retinopathy but without rubeosis had significantly increased levels of IGF-I and IGFBP2 in their vitreous fluid the changes, about twofold relative to nonischemia controls and thus much smaller than those seen in rubeosis patients. IGF-II and IGFBP-3 were not significantly increased compared to nonischemia controls. The relative increase in IGFBP- 2 was $35 \%$ of that observed in rubeosis patients, while that of IGFBP-3 was only $5 \%$ of that seen in the rubeosis group. In particular, the lack of increase of IGFBP-3 was remarkable since a 13-fold increase was present in severe ischemia of rubeosis and therefore even a relatively small rise would have been easily detectable. A possible explanation for the uneven increases of IGFBP-2 and IGFBP-3 in diabetes and rubeosis is that regulatory events inherent to diabetes might interfere with the local regulation of these factors apart from ischemia. For example, a metabolic suppression of IGFBP-3 by the diabetes may prevent increases in response to ischemia. Similarly, an increase in IGFBP-2 in the pituitary, kidney, and liver, but not in neural tissue, of experimental diabetic rats was recently described (24). The marked increase in IGFBP-2 might thus relate to the metabolic situation in the diabetic patients. A remarkably high degree of correlation was noted between levels of IGF-II and IGFBP-2 in proliferative diabetic retinopathy, while such a correlation was not seen for IGF-I and IGFBP-3. This may be explained by the high binding affinity of IGF-II for IGFBP-2, although the same holds true for
IGF-I and IGFBP-3. An alternative explanation is that some regulatory relation may exist between IGF-II and IGFBP-2 in the retina, which may be maintained in diabetes.

In diabetic subjects with rubeosis large increases of all components of the IGF system were observed, which closely paralleled those seen in nondiabetic subjects with rubeosis. This supports the interpretation that the ischemic stimulus triggered similar increases of all components of the IGF system irrespective of the diabetes. The more localized ischemia occurring in proliferative diabetic retinopathy without rubeosis probably triggers a smaller response compatible with a less intense stimulus of ischemia. The experimental work of Grant et al. (11), which compared intravitreal or local retinal application of IGF-I in rabbits ( see Introduction ), also supports this interpretation.

Grant et al. (10) previously reported a 2.3-fold increase of IGF-I and no change of IGF-II in vitreous fluid obtained from diabetic subjects relative to controls. Both the absolute values and the relative increases of IGF-I and -II closely parallel the data from our study. However, the study of Grant et al. (10) did not include a group with ischemic eye disease, and therefore interpreted the changes of IGF-I in the context of the diabetes. In view of the powerful increase of IGF-I in rubeosis, which was probably triggered by ischemia, this condition needs to be considered as causative for increases of IGF-I in the vitreous of patients with diabetic retinopathy. The question arising is whether increases of IGF-I and of other components of this system precede the onset of diabetic retinopathy or whether these increases are a consequence of ischemia due to diabetic microvascular angiopathy. This question cannot be answered with the currently available methodology. The data provided, however, favor the concept that it is ischemia that triggers increases of IGF components in diabetic retinopathy.

The mRNA for type I IGF receptors has been demonstrated in retinal pigment epithelial cells (25), and type I IGF receptors have been demonstrated in neural mammalian retinal tissue (26), which provides evidence that IGF-I and -II may exert direct effects on the retina. The presence of receptors for IGF on vascular cells in the eye has to our knowledge not been demonstrated (27), although growth-promoting effects of IGF-I were shown (11). A role for IGF in angioneogenesis remains to be firmly established although the permissive actions of IGF on proliferative processes suggest a promoting function of IGF components in angioneogenesis, as was shown in the human and rabbit eye $(11,12)$.

IGFBP-3 is thought to enhance the action of IGF-I (21, 28). IGFBP-2 has been shown to inhibit actions of IGF-I and IGF-II under certain conditions $(29,30)$, but its effects in the complex biological environment of the vitreous is difficult to predict. The prevailing effect appears to be an enhancement of the mitogenic actions of IGF-I and -II mediated by diverse mechanisms (21).

In this study, the eye was used as a model system to study effects of ischemia on a particular growth factor system. Previous studies of ischemia models were concentrated on the angiogenic factors of the fibroblast and tumor necrosis factor families released by macrophages $(1,2)$. Although the response observed may be highly specific to the ocular system, it appears more likely that hypoxia represents a general stimulus for the activation of the IGF system. It should therefore be of interest to examine the responses of various cell types regarding components of the IGF system to experimental hypoxic conditions. 


\section{Acknowledgments}

This work is dedicated to Professor Dr. G. Paumgartner (Munich) on occasion of his 60 th birthday.

This study was supported by the Deutsche Diabetesgesellschaft. A. Pfeiffer is recipient of a Hermann and Lilly-Schilling Professorship.

\section{References}

1. Hunt, T. K., editor. 1980. Wound Healing and Wound Infection: Theory and Surgical Practice. Appleton Century Crofts, New York. 1-272.

2. Klagsbrun, M., and J. Folkman. 1990. Angiogenesis. In Peptide Growth Factors and Their Receptors II. Handbook of Experimental Pharmacology, vol. 95/II. M. B. Sporn and A. B. Roberts, editors. Springer-Verlag, Berlin, p. 549586.

3. Patz, A. 1982. Clinical and experimental studies on retinal neovascularization. Am. J. Ophthalmol. 94:715-743.

4. Shimizu, K., Y. Kobayashi, and K. Muraoka. 1981. Midperipheral fundus involvement in diabetic retinopathy. Ophthalmology. 88:601-609.

5. Meyer-Schwickerath, G., ed. 1960. Light Coagulation. C. V. Mosby, St. Louis. 71-74.

6. Meyer-Schwickerath, R., D. Neuerburg-Heusler, and M. Schulte. 1988 Ischämische Ophthalmopathie, Ursache und Differentialdiagnose. Fortshr. Oph thalmol. 85:789-792.

7. McAvoy, J. W., and C. G. Chamberlain. 1990. Growth factors in the eye. Prog. Growth Factor Res. 2:29-43.

8. Merimee, T. J. 1990. Diabetic retinopathy. N. Engl. J. Med. 322:978-982.

9. Flyvbjerg, A. 1990. Growth factors and diabetic complications. Diabetic Medicine. 7:387-399.

10. Grant, M., B. Russel, C. Fitzgerald, and T. J. Merimee. 1986. Insulin-like growth factors in the vitreous. Diabetes. 35:416-420.

11. Grant, M. B., R. N. Mames, C. Fitzgerald, E. A. Ellis, M. Aboufriekha and J. Guy. 1993. Insulin-like growth factor I acts as an angiogenic agent in rabbit cornea and retina: comparative studies with basic fibroblast growth factor. Diabetologia. 36:282-291.

12. Hyldahl, L., W. Engstrom, and P. N. Schofield. 1986. Stimulatory effect of insulin-like growth factors on DNA synthesis in the human embryonic cornea. $J$. Embryol. Exp. Morphol. 98:71-83.

13. Breier, B. H., B. W. Gallaher, and P. D. Gluckmann. 1991. Radioimmunoassay for insulin-like growth factor I (IGF I): Solution to some problems and pitfalls. J. Endocrinol. 128:347-357.

14. Blum, W. F., M. B. Ranke, and J. R. Bierich. 1986. Isolation and partial characterization of six somatomedin-like peptides from human plasma Cohn fraction IV. Acta Endocrinol. 111:271-284.

15. Blum, W. F., B. Breier, P. Gluckmann, and M. B. Ranke. 1992. A novel
IGFBP blocked IGF-I RIA that measures what it pretends to measure: IGF-I Acta Endocrinol. 126(Suppl. 4):76. (Abstr.)

16. Blum, W. F., M. B. Ranke, and J. R. Bierich. 1988. A specific radioimmunoassay for insulin-like growth factor II: interference of IGF-binding proteins can be blocked by excess IGF-I. Acta Endocrinol. 118:374-380.

17. Blum, W. F., M. B. Ranke, K. Kietzmann, E. Gauggel, H. J. Zeisel, and J. R. Bierich. 1990. A specific radioimmunoassay for the growth hormone (GH)dependent somatomedin binding protein: its use for diagnosis of growth hormone deficiency. J. Clin. Endocrinol. \& Metab. 70:1292-1298.

18. Blum, W. F. 1992. Insulin-like growth factors and their binding proteins. In Functional Endocrinologic Diagnostics in Children and Adolescents. M. B. Ranke, editor. J \& J Verlag, Mannheim, Germany. 101-117.

19. Blum, W. F., N. Horn, J. Kratzsch, J. O. Jorgensen, and M. B. Ranke. 1992. Measurements of human insulin like growth factor binding protein 2 (hIGFBP-2) by a specific RIA. Acta Endocrinol. 126(Suppl. 4):77. (Abstr.)

20. Laatikainen, L., and R. K. Blach. 1977. Behaviour of the iris vasculature in central retinal vein occlusion. A fluorescein angiographic study of the vascular response of the retina and iris. Br. J. Ophthalmol. 61:272-281.

21. Clemmons, D. R. 1990. Insulinlike growth factor binding proteins. Trends Endocrinol. Metab. I:412-417.

22. Clemmons, D. R., J. P. Thissen, M. Maes, J. M. Ketelslegers, and L. E. Underwood. 1989. Insulinlike growth factor I infusion into hypophysectomized protein deprived rats induces specific IGF binding proteins in serum. Endocrinology. 125:2967-2973.

23. Zapf, J., C. Hauri, M. Waldvogel, and E. R. Froesch. 1989. Recombinant human insulin-like growth factor I induces its own specific carrier protein in hypophysectomized and diabetic rats. Proc. Natl. Acad. Sci. USA. 86:3818-3822.

24. Gelato, M. C., D. Alexander, and K. Marsh. 1992. Differential regulation of insulinlike growth factor binding proteins in experimental diabetes mellitus in the rat. Diabetes. 41:1511-1519.

25. Martin, D. M., D. Yee, and E. L. Feldman. 1992. IGF-I receptor mRNA in retinal pigment epithelial cells. Mol. Brain Res. 12:181-186.

26. Ocrant, I., K. L. Valentino, M. G. King, T. H. Wimpy, R. G. Rosenfeld, and D. G. Baskin. 1989. Localization and structural characterization of insulinlike growth factor receptors in mammalian retina. Endocrinology. 125:24072413.

27. King, G. L., A. D. Goodman, S. Buzney, A. Moses, and C. R. Kahn. 1985. Receptors and growth promoting effects of insulin and insulin-like growth factors on cells from bovine retinal capillaries and aorta. J. Clin. Invest. 75:1028-1036.

28. Blum, W. F., R. W. Jenne, F. Reppin, K. Kietzmann, M. B. Ranke, and J. R. Bierich. 1989. Insulin-like growth factor I (IGF-I)-binding protein complex is a better mitogen than free IGF-I. Endocrinology 125:766-771.

29. Knaur, D. J., and G. L. Smith. 1980. Inhibition of biologic activity of multiplication stimulating activity by binding to its carrier protein. Proc. Natl. Acad. Sci. USA. 77:7252-7255.

30. Ross, M., G. L. Francis, L. Szabo, J. C. Wallace, and F. J. Ballard. 1989. Insulin-like growth factor (IGF)-binding proteins inhibit the biological activities of IGF-I and IGF-II but not des-(1-3)-IGF-I. Biochem. J. 258:267-276. 